www.jmscr.igmpublication.org

Index Copernicus Value: 79.54

ISSN (e)-2347-176x ISSN (p) 2455-0450

crossrefDOI: https://dx.doi.org/10.18535/jmscr/v7i3.150

Journal Of Medical Science And Clinical Research

IGM Publication

An Official Publication of IGM Publication

\title{
Role of MRI in Evaluation of Uterine and Adnexal Pathologies
}

\author{
Dr Vanshika Kohli ${ }^{1 *}$, Dr P S Mishrikotkar ${ }^{2}$, Dr Asmita Suryawanshi ${ }^{3}$ \\ ${ }^{\mathbf{1}}$ Resident, ${ }^{\mathbf{2}}$ Professor and HOD, ${ }^{\mathbf{3}}$ Associate Professor \\ Department of Radiology, MGM Medical College Aurangabad (MS) India \\ *Corresponding Author \\ Dr Vanshika Kohli \\ Resident, Department Of Radiology, MGM Medical College Aurangabad (MS) India
}

\begin{abstract}
Introduction: Uterine and adnexal masses are one of the common causes of gynecological consultations. These masses may be due to physiological and benign conditions or may suggest presence of more sinister pathologies such as uterine or adnexal malignancies. The multi-planar capabilities along with superior contrast resolution has made magnetic resonance imaging (MRI) an excellent modality of choice for proper depiction of female uterine and adnexal anatomy. It has got superior sensitivity and specificity in the diagnosis of uterine and adnexal pathologies as compared to any other available imaging technique. There for we conducted this prospective study to analyze the role of MRI in evaluation of uterine and adnexal pathologies

Materials and Methods: This was a prospective observational study in which 75 female patients who came to the radiology department with uterine and adnexal pathologies were included on the basis of a predefined inclusion and exclusion criteria. Institutional ethical committee approved the study and informed consent was obtained from all the participants. All patients underwent MRI imaging examinations were performed on a PHILIPS MULTIVA 1.5T. Imaging was performed using a pelvic coil with the patient in supine position. Gadodiamide $10 \mathrm{ml}$ was administered as and when required. Collected data was compiled in MS Excel sheet 2007 for analysis of this data SPSS version 20th software shall be used. Qualitative data was represented in form of frequency and percentile. Quantitative data was represented in the form of mean, standard deviation, etc. $P$ value less than 0.05 was taken as statistically significant.

Results: A total 75 women were included in this study. The mean age of the studied cases was found to be 38.73 +/- 18.62 years. The common presenting complaints were found to be post-menopausal bleeding (32\%) followed by abdominal pain (24\%) and menstrual irregularities (18.7\%). The most common etiology of the mass was found to be neoplastic (29.3\%) followed by congenital abnormalities (25.3\%). 25 (33.3\%) patients were found to have malignant neoplastic lesions. The Anatomical distribution of mass lesions showed that the common locations were uterus (60\%), cervix (17.3\%) or adnexa (18.7\%). The most common abnormalities diagnosed were carcinoma cervix (20.97\%), bicornuate (11.29\%) and hypoplastic uterus (11.29\%). Amongst the patients having adnexal pathologies the most common lesion was found to be complex ovarian cyst (35.7\%) and the most common congenital anomaly was found to be bicornuate uterus which was seen in 7/21 $(33.33 \%)$ patients. Majority of the adnexal pathologies were either cysto-solid (7/13) or cystic (5/13) whereas all vaginal and cervical lesions were solid on imaging characteristics. Contrast enhancement was seen in all 46 patients in whom contrast was given and heterogeneous contrast enhancement was seen in majority (69.6\%) of the patients. Out of 13 patients having carcinoma cervix 7 patients had stage II (A or B) cancer
\end{abstract}


whereas amongst 5 patients with ovarian carcinoma 4 (80\%) patients had stage 1A cancer. There were 2 patients with endometrial carcinoma and both of them had stage IB cancer. Out of 51 samples sent for histopathology correlation of HPE with MR diagnosis was seen in 49 (96\%) patients.

Conclusion: MRI is found to be an excellent imaging technique for the diagnosis of uterine and adnexal pathologies. It has got a high sensitivity and specificity for the diagnosis of congenital as well as benign and malignant pathologies of uterus and adnexa.

Keywords: Uterine and adnexal pathologies, Magnetic resonance imaging, contrast enhancement, Staging.

\section{Introduction}

The multiplanar capabilities along with superior contrast resolution has made magnetic resonance imaging (MRI) a modality of choice for proper depiction of female uterine and adnexal pathology and very often leads to specific diagnosis. It also has additional benefits including absence of ionizing radiation. It moreover obviates the need for using nephrotoxic contrast material in a good number of patients. MRI is a very useful tool in patients especially in cases where ultrasonography is inconclusive or suboptimal ${ }^{1}$. MRI has time and again proven to be an excellent modality for accurate staging of known cases of endometrial carcinoma $^{2}$. By making use of a combination of T2 weighted imaging and Gadolinium-enhanced MRI, it is possible for us to readily differentiate between superficial and deep-muscle-invasive masses. It is an excellent modality of choice particularly for pre-surgical characterization as well as staging of carcinoma of endometrium, cervix and ovaries and, hence plays a crucial role in stratifying the patients into appropriate treatment options. The role of Magnetic resonance imaging in endometrial cancer includes the evaluation of depth of myometrial invasion, cervical invasion, and nodal metastasis. MRI has been proven to be significantly better than CT and ultrasound in diagnosing myometrial invasion, extension of tumor margins to the cervix and in assessing nodal involvement. MRI is not initially used to diagnose cervical cancer but is used to stage disease in women who have had a diagnosis established by a Pap smear or biopsy ${ }^{3}$. MR imaging can obviate invasive procedures, such as cystoscopy, proctoscopy, and sigmoidoscopy thereby reducing staging costs and morbidity. MRI is a problem solving tool and modality of choice in the diagnosis and evaluation of uterine leiomyomas pre and post treatment with uterine artery embolization ${ }^{4}{ }^{5}$. Multiple studies have proven that MRI is superior to ultrasound for the confirmed diagnosis of diffuse and focal adenomyosis $^{6}$. MRI is used to confirm uterine agenesis or hypoplasia of uterus in women with complaints of primary amenorrhea. It is also used to evaluate associated genito-urinary abnormalities such as renal agenesis, ectopia and crossed fused ectopia ${ }^{7}$.

In women with infertility, MRI confirms the presence of septate uterus or bicornuate uterus and helps in defining the fibrous and muscular components. MRI has a great role in the preprocedural and post-procedural evaluation for uterine artery embolization, diagnosis of diffuse and focal adenomyosis, accurate staging of known endometrial and cervical carcinoma, detailed evaluation of clinically suspected müllerian anomalies, and in preprocedural workup for uterine prolapse. Introduction of newer techniques like diffusion-weighted imaging has improved the detection and potentially the characterization of small uetro-ovarian tumors and the visualization of small peritoneal deposits, which significantly impacts patient management ${ }^{8}$. ADC measurement may be useful for monitoring the therapeutic outcome after uterine arterial embolization, chemotherapy and/or radiation therapy ${ }^{9}$ Dynamic contrast enhanced MRI (DCE-MRI) has the potential to improve tumor detection and local staging, and can also provide quantitative information about uterine and cervical tumor perfusion, which may be useful for both monitoring therapeutic effects and predicting therapeutic outcome ${ }^{10}$. Thorough knowledge of the spectrum of MR imaging features of various 
physiologic variations and pathologic conditions that affect the female pelvis and is essential for establishing an accurate diagnosis and guiding further management. In the present scenario MRI is widely used to evaluate uterine and adnexal pathologies owing to its high contrast resolution and its excellent ability to provide tissue characterization as well as its multiplanar imaging capabilities.

We conducted this prospective study to analyze the role of MRI in evaluation of uterine and adnexal pathologies

\section{Materials and Methods}

This was a prospective observational study conducted in the department of Radiology, MGM Medical College and Hospital, Aurangabad over a period of 2 years (November 2016 to November 2018). Institutional Ethical committee duly approved the study. All patients with clinically suspected uterine and adnexal masses referred for imaging were included in this study on the basis of a predefined inclusion and exclusion criteria. Patients were advised to fast for at least 4 hours before examination and were asked to empty the bladder and bowel just before examination as it reduces blurring from motion and ghost artifacts which occur due to bowel peristalsis. In selected patients antispasmodics, such as glucagon (0.5-1.0 $\mathrm{mg}$ IV/IM) or hyoscine butylbromide $20-40 \mathrm{mg}$ IM/IV were given.

\section{MRI protocol}

All MRI imaging examinations were performed on a PHILIPS MULTIVA 1.5T. Imaging was performed using a pelvic coil with the patient in supine position. Procedure was explained to patients and their relatives in the language best understood by them. Informed written consent was taken. Risks and complications related to contrast study were explained. Detailed history of complaints, previous medical and surgical conditions was taken. Presence of any implants (aneurysmal clips, cochlear implants etc.) was ruled out by asking appropriate questions.
Positioning of the patient was done (head first, supine). Sedatives were given as and when required (very young patients with chances of motion during the study, claustrophobic patients). Initially a localizer scan was performed in transverse, sagittal and coronal orientation. This was followed by T1W/TSE - axial, coronal and sagittal planes; T2W/TSE -axial, coronal and sagittal planes; T2W SPAIR - coronal, sagittal planes; Small FOV T2WTSE -coronal planes. Gadodiamide $10 \mathrm{ml}$ was administered as and when required at rate of $2 \mathrm{ml} / \mathrm{sec}$. Post contrast T1 fat saturated images were obtained in axial, coronal and sagittal planes. The parameters included matrix size of 192-256 x 256-512, field of view (appropriate to body habitus); 230-250 $\mathrm{mm}$ for the body coil, and 3-4 mm section thickness with an intersection gap of 30-40\%.Post processing was done by inbuilt software.

Collected data was compiled in MS Excel sheet 2007 for analysis of this data SPSS version 20th software was used. Qualitative data was represented in form of frequency and percentile. Quantitative data was represented in the form of mean and standard deviation. Both qualitative and quantitative data will be represented in the form of visual impression like bar diagram, pie diagram, etc. To check the association between different parameters, chi square test was applied. 'P' value less than 0.05 was taken as statistically significant.

\section{Inclusion criteria}

1. All patients with clinically suspected uterine and adnexal masses.

2. For staging of known malignant conditions.

3. Patients of all age groups.

4. Those who consented to be part of study.

\section{Exclusion criteria}

1. Cases suspected to be ectopic pregnancy.

2. All Patients having cardiac pacemakers, prosthetic heart valves, cochlear implants or any metallic implants.

3. Patients having history of claustrophobia.

4. All patients who refused consent to be a part of the study. 


\section{JMSCR Vol||07||Issue||03||Page 861-874||March}

\section{Results}

In this study total 75 patients were included. The most common age group was found to be 21-30 years $(21.3 \%)$ followed by $41-50(20 \%)$ years and $11-20$ years $(18.7 \%)$. The mean age of the patients was found to be $38.73+/-18.62$ years.

Table 1: Age groups of the studied cases

\begin{tabular}{|l|c|c|}
\hline Age Groups & No Of Patients & Percentage \\
\hline$<10$ years & 2 & $2.67 \%$ \\
\hline $11-20$ years & 14 & $18.67 \%$ \\
\hline $21-30$ years & 16 & $21.33 \%$ \\
\hline $31-40$ years & 8 & $10.67 \%$ \\
\hline $41-50$ years & 15 & $20.00 \%$ \\
\hline $51-60$ years & 9 & $12.00 \%$ \\
\hline $61-70$ years & 8 & $10.67 \%$ \\
\hline$>70$ years & 3 & $4.00 \%$ \\
\hline Total & 75 & $100 \%$ \\
\hline Mean Age: $\mathbf{3 8 . 7 3}+/ \mathbf{~ 1 8 . 6 2}$ years. \\
\hline
\end{tabular}

The analysis of signs and symptoms of the studied cases showed that the most common symptom was post-menopausal bleeding (32\%). Other clinical symptoms were pain in abdomen which was seen in $18(24 \%)$ of our patients followed by irregular menses (18.67\%). Weight loss, amenorrhea and bleeding per vaginum was seen in $13(17.33 \%), 10(13.33 \%)$ and 9(12\%) patients respectively. Bleeding per vaginum was seen in 9 $(12 \%)$ patients. Mass per abdomen was seen in patients. Infertility was seen in $8(10.67 \%)$ patients. Thus the most common complaint in our study was seen in post-menopausal women in the form of post-menopausal bleeding.

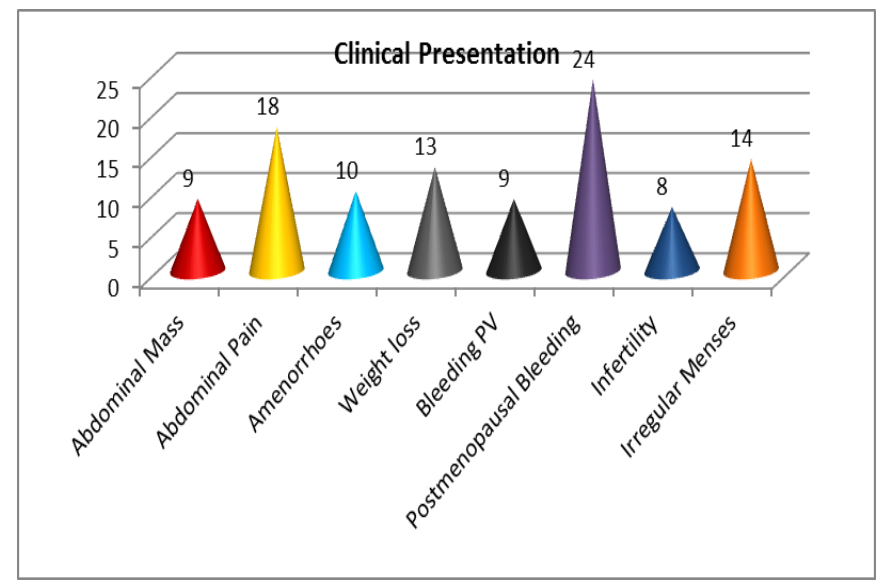

Figure 1: Clinical Presentation in the studied cases.
In this study most common etiology of adnexal mass was found to be neoplastic with 22 patients $(29.3 \%)$ having pathologies due to neoplastic etiology followed by 19 patients $(25.3 \%)$ with pathologies related to congenital anomalies. Pathologies due to infective etiology was found in 10 patients $(13.3 \%)$. The last group consisted of pathologies due to other etiologies (Idiopathic, hormonal or degenerative).

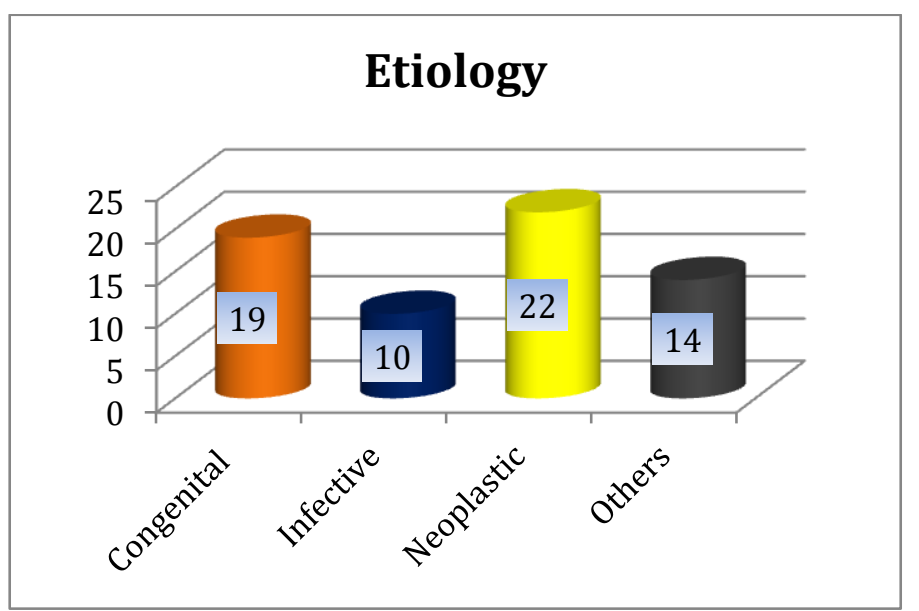

Figure 2: Etiology of uterine and adnexal masses in studied cases.

The pathologies were divided into benign, malignant and congenital. It was found that out of the studied cases 29 (38.67\%) patients had benign pathologies. Malignant and congenital abnormalities were found in $25(33.33 \%)$ and 21 $(28.00 \%)$ patients respectively.

Table 2: Pathologies in studied cases

\begin{tabular}{|l|c|c|}
\hline Pathology & No Of Patients & Percentage \\
\hline Benign & 29 & $38.67 \%$ \\
\hline Malignant & 25 & $33.33 \%$ \\
\hline Congenital & 21 & $28.00 \%$ \\
\hline Total & $\mathbf{7 5}$ & $\mathbf{1 0 0 . 0 0 \%}$ \\
\hline
\end{tabular}

The lesions were classified according to the structures primarily involved. It was found that Uterus was involved in 45 patients $(60 \%)$ whereas ovaries and adnexa were involved in 14 patients $(18 \%)$. The other sites of primary pathologies were cervix $(17 \%)$ followed by vulva $(2.7 \%)$ and vagina $(1.3 \%)$ respectively. Hence uterus was found to be most commonly involved structure in our study. 


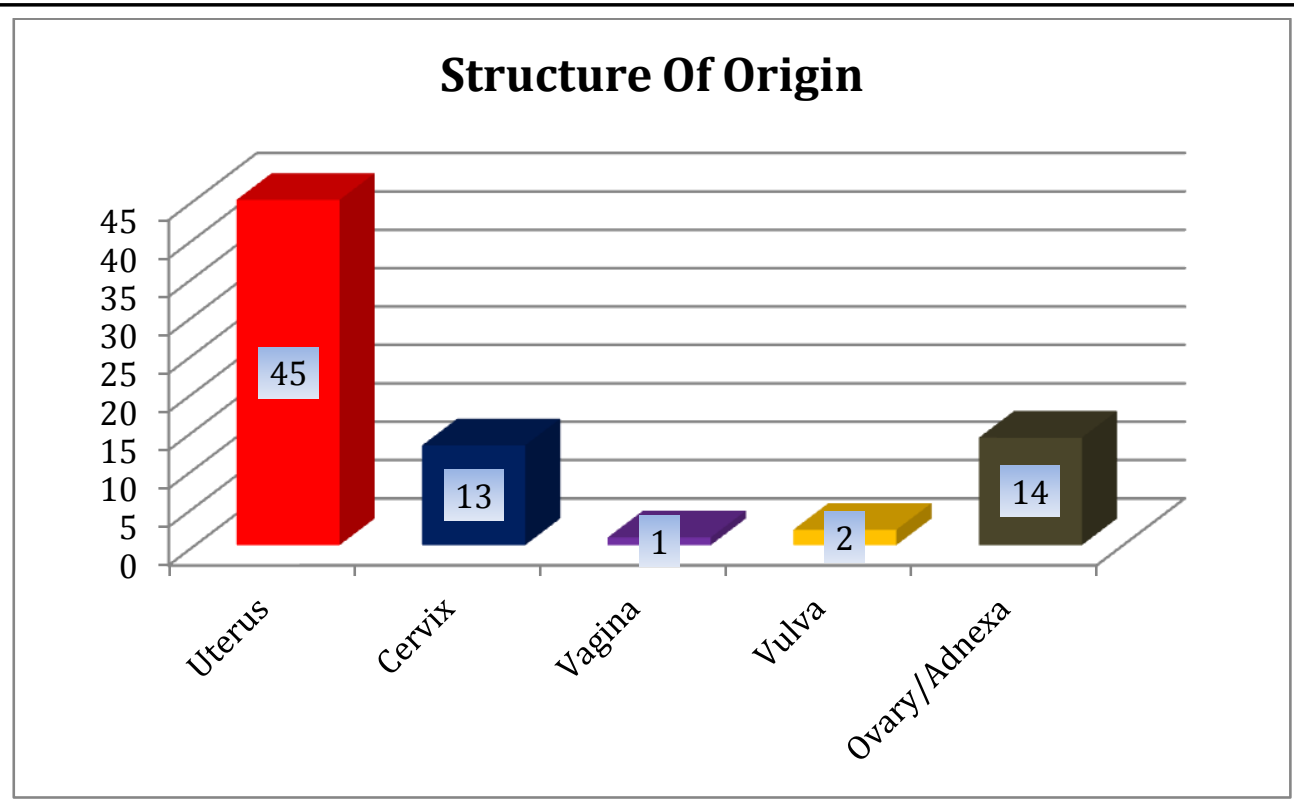

Figure 3: Anatomical Origin of the lesion.

The most common uterine pathology in our study was found to be carcinoma cervix (17.33\%) followed by hypoplastic $(9.33 \%)$ and bicornuate uterus $(9.33 \%)$. The other common pathologies were found to be uterine fibroid $(8.00 \%)$, uterine agenesis (6.67\%) and adenomyosis (6.67\%). Least common pathologies were found to be Arcuate uterus, Subseptate uterus and arteriovenous malformations which were seen in 1 (1.61\%) patient each.

Table 4: Distribution of uterine pathologies

\begin{tabular}{|l|c|c|}
\hline Pathologies & No of patients & Percentage \\
\hline Fibroids & 6 & $8.00 \%$ \\
\hline Adenomyosis & 5 & $6.67 \%$ \\
\hline Endometrial Hyperplasia & 3 & $4.00 \%$ \\
\hline F.Polyp & 4 & $5.33 \%$ \\
\hline Ca Cervix & 13 & $17.33 \%$ \\
\hline Ca Endometrium & 2 & $2.67 \%$ \\
\hline Ca Vagina & 3 & $4.00 \%$ \\
\hline Bicornuate Uterus & 7 & $9.33 \%$ \\
\hline Arcuate Uterus & 1 & $1.33 \%$ \\
\hline Subseptate Uterus & 1 & $1.33 \%$ \\
\hline Agenesis & 5 & $6.67 \%$ \\
\hline AVM & 1 & $1.33 \%$ \\
\hline Haematometra & 2 & $2.67 \%$ \\
\hline GTN & 2 & $2.67 \%$ \\
\hline Hypoplastic Uterus & 7 & $9.33 \%$ \\
\hline Total & $\mathbf{6 2}$ & $\mathbf{1 0 0 \%}$ \\
\hline
\end{tabular}




\section{JMSCR Vol||07||Issue||03||Page 861-874||March}

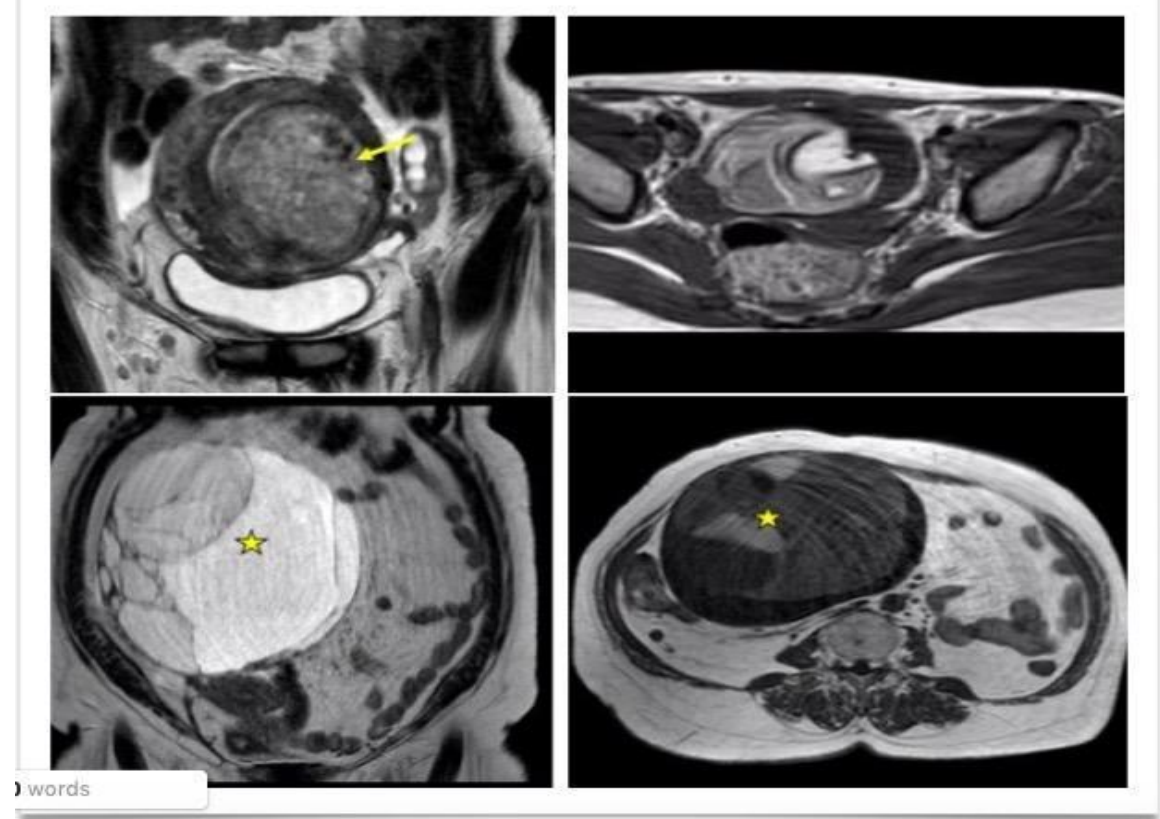

Figure 4: (Clockwise from left upper corner). Fibroid, dermoid cyst, T2W and T1W images showing ovarian mucinous cystadenoma

The analysis of ovarian pathologies showed that majority of the patients with ovarian pathologies had complex ovarian cyst $(35.71 \%)$ followed by patients having unilateral hydrosalpinx (14.29\%), bilateral hydrosalpinx (14.29\%) and bulky polycystic ovaries (14.29\%).Other pathologies seen in our study were simple ovarian cysts(7.14\%), dermoid cyst(7.14\%) and agenesis of ovaries $(7.14 \%)$. Overall most common ovarian pathology was found to be complex unilateral ovarian cyst.

Table 4: Distribution of ovarian pathologies

\begin{tabular}{|l|c|c|}
\hline Age Groups & No Of Patients & Percentage \\
\hline Complex cyst & 5 & $35.71 \%$ \\
\hline Unilateral Hydrosalpinx & 2 & $14.29 \%$ \\
\hline Bilateral Hydrosalpinx & 2 & $14.29 \%$ \\
\hline Bulky polycystic Ovaries & 2 & $14.29 \%$ \\
\hline Simple cyst & 1 & $7.14 \%$ \\
\hline Dermoid cyst & 1 & $7.14 \%$ \\
\hline Agenesis of Ovaries & 1 & $7.14 \%$ \\
\hline Total & $\mathbf{1 4}$ & $\mathbf{1 0 0 . 0 0 \%}$ \\
\hline
\end{tabular}
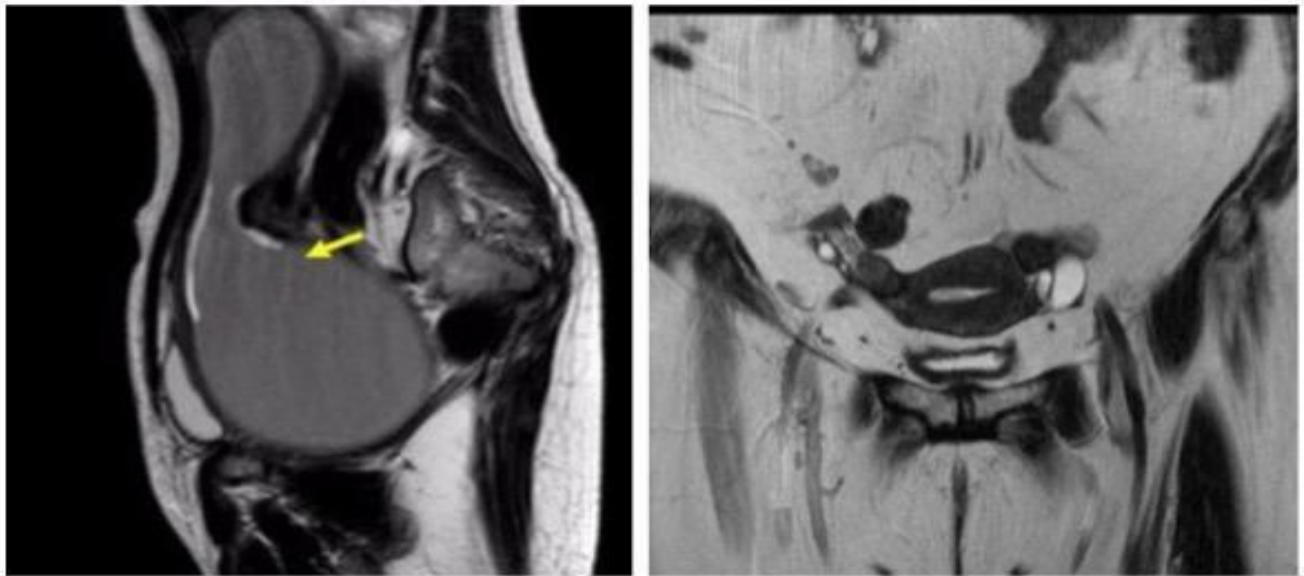

Figure 5: MRI images showing Haematometra with haematocolpos (Left), Left Hydrosalpinx (Right). 


\section{JMSCR Vol||07||Issue||03||Page 861-874||March}

The distribution of the cases on the basis of type of congenital anomalies showed that out of 21 patients with congenital anomalies the most common anomalies were bicornuate and hypoplastic uterus which were seen in $7(33.33 \%)$ patients each followed by uterine agenesis $(23.81 \%)$. Bicornuate and Arcuate uterus was seen in $1(4.76 \%)$ patient each.

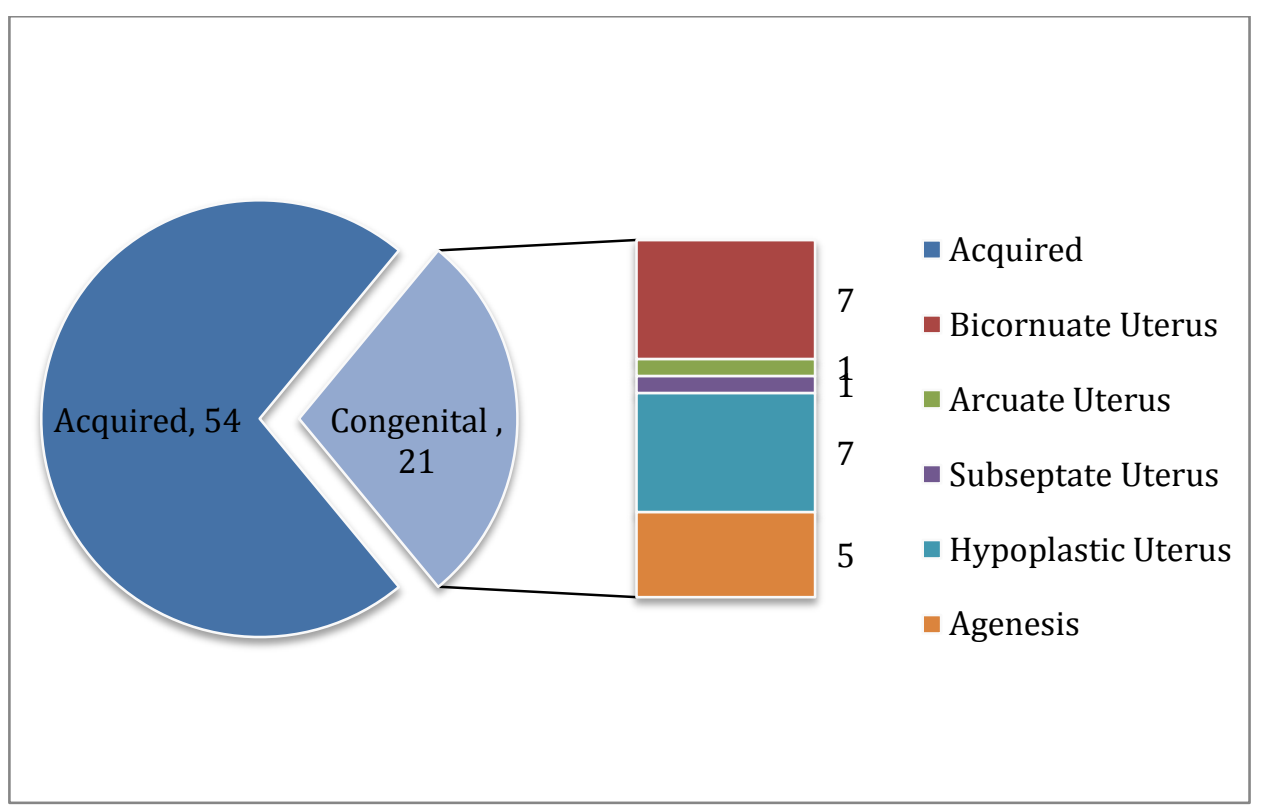

Figure 6: Distribution of cases on the basis of congenital anomalies.
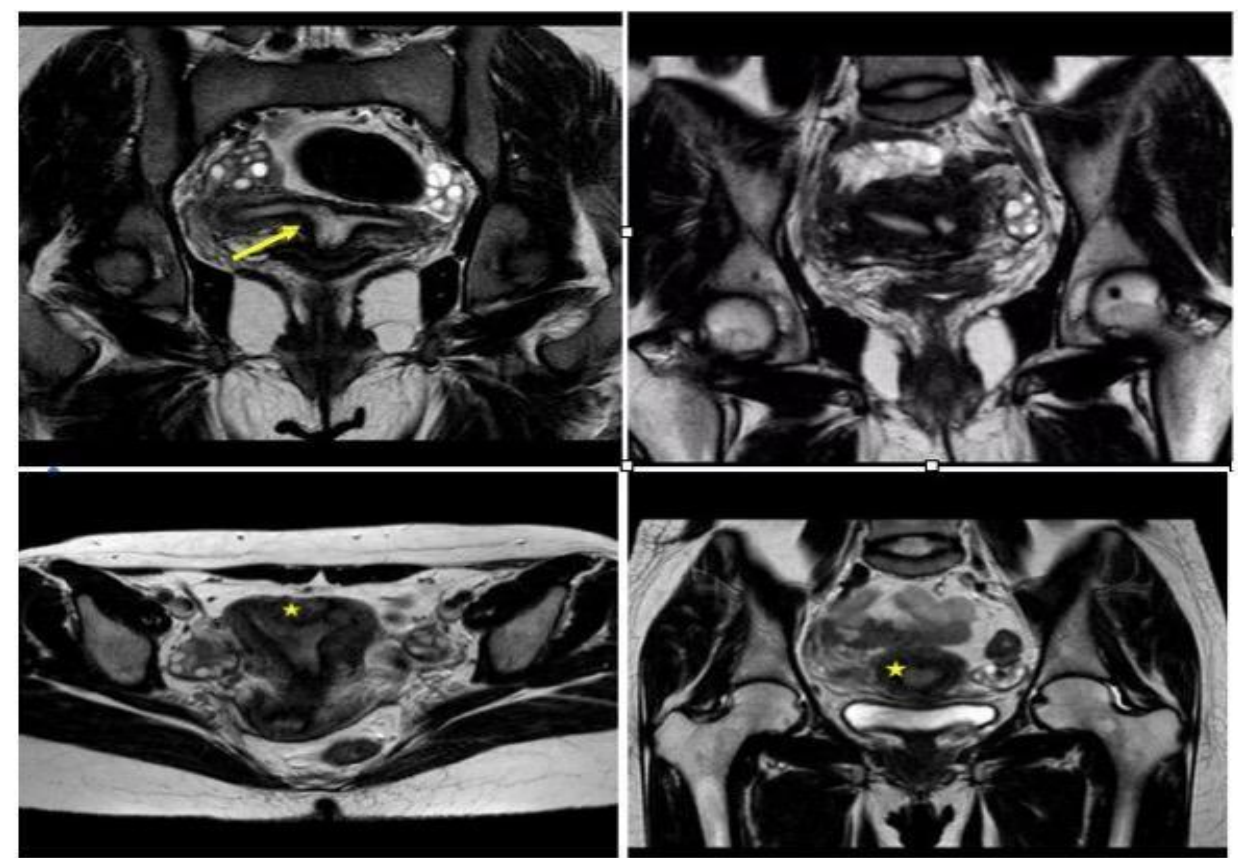

Figure 7: Congenital Uterine Anomalies (Clockwise from left upper corner). Bicornuate Uterus, Bicornuate bicolis uterus, arcuate uterus and subseptate uterus

The maximum numbers of uterine lesions were solid in nature (n-20). Maximum number of cervical lesions (n-13) and lesions of vagina and vulva (n-3) were solid in nature .Maximum number of lesions in ovary and adnexa were solid- cystic in nature (n-7). 5 ovarian/adnexal lesions were purely cystic in nature. There was a statistically significant difference in tissue characteristics of the studied cases $(\mathrm{P}<0.0001)$. 
Table 5: Distribution of patients according to anatomical structure/origin based on tissue characteristics

\begin{tabular}{|l|c|c|c|c|c|c|}
\hline \multirow{2}{*}{ Tissue Character } & \multicolumn{3}{|c|}{ Tissue content and anatomical origin of lesions } & Chi- square \\
value & P-value \\
\cline { 2 - 5 } & Uterine & cervix & vagina vulva & $\begin{array}{c}\text { ovary } \\
\text { /adnexa }\end{array}$ & & \\
\hline Solid & 20 & 13 & 3 & 0 & & \\
\hline Cystic & 1 & 0 & 0 & 5 & \multirow{2}{*}{80.6} & P $<0.0001$ \\
Solid \& Cystic & 0 & 0 & 0 & 7 & \\
\cline { 1 - 5 } Not Applicable & 25 & 0 & 0 & 1 & & Significant \\
\hline Total & 46 & 13 & 3 & 13 & \\
\hline
\end{tabular}

The analysis of the patients on the basis of pathologies (Whether benign, malignant or congenital) showed that in the benign pathologies the most common affected age group was found to be in between 41-50 years (10/29) whereas majority of the patients having pathologies belonged to age group above 50 years of age (15/25). All patients (100\%) with congenital anomalies were diagnosed before 30 years of age.

Table 6: Age distribution of benign, malignant and congenital pathologies

\begin{tabular}{|l|c|c|c|}
\hline Age (yrs) & Benign & Malignant & Congenital \\
\hline$<=10$ years & 2 & 0 & 0 \\
\hline $11-20$ & 3 & 0 & 10 \\
\hline $21-30$ & 5 & 2 & 11 \\
\hline $31-40$ & 4 & 3 & 0 \\
\hline $41-50$ & 10 & 5 & 0 \\
\hline $51-60$ & 3 & 6 & 0 \\
\hline $61-70$ & 2 & 6 & 0 \\
\hline$>70$ & 0 & 3 & 0 \\
\hline Total & $\mathbf{2 9}$ & $\mathbf{2 5}$ & $\mathbf{2 1}$ \\
\hline
\end{tabular}

The maximum numbers of patients were seen having cervical carcinoma (n-13). Out of these patients, majority were belonging to age group 41$70(n=9)$ years and none in the age group of $0-10$ years. There were 2 patients each in age groups of 11-40 years and more than 70 years. Ovarian carcinoma was seen in 6 patients .Out of these 3 patients belonged to the age group of $41-70$ years followed by 2 patients in the age group of 11-40 years and 1 patient in the age group of more than
70 years. Carcinoma of vagina was seen in one patient and carcinoma of vulva was observed in 2 patients all three of them belonged to the age group of 41-70 years. Carcinoma of endometrium was observed in two patients, both of them belonging to age group of $41-70$ years. Other malignancies including gestational trophoblastic neoplasm which was seen in one patient (n-1) in the age group of 11-40 years.

Table 7: Age distribution of patients according to malignant lesions

\begin{tabular}{|c|c|c|c|c|c|c|c|}
\hline \multirow[t]{2}{*}{ Age-Group } & \multicolumn{5}{|c|}{ Malignant Lesions } & \multirow{2}{*}{$\begin{array}{l}\text { Chi- } \\
\text { square } \\
\text { value }\end{array}$} & \multirow[b]{2}{*}{ P-value } \\
\hline & Ca endo & Ca cervix & $\begin{array}{c}\text { Ca ovary \& } \\
\text { adnexa }\end{array}$ & $\begin{array}{l}\text { vagina } \\
\& \text { vulva }\end{array}$ & Other & & \\
\hline$>10$ years & 0 & 0 & 0 & 0 & 0 & \multirow{5}{*}{19.39} & \multirow{5}{*}{$\begin{array}{l}\mathrm{P}<0.0001 \\
\text { Significant }\end{array}$} \\
\hline $11--40$ & 0 & 2 & 2 & 0 & 1 & & \\
\hline $41-70$ & 2 & 9 & 3 & 3 & 0 & & \\
\hline$>70$ & 0 & 2 & 1 & 0 & 0 & & \\
\hline Total & 2 & 13 & 6 & 3 & 1 & & \\
\hline
\end{tabular}

Correlation of diagnosis on MRI with histopathological diagnosis was done. MR diagnosis of maximum number of patients correlated with histopathology (n-49). Only 2 patients showed no correlation. 


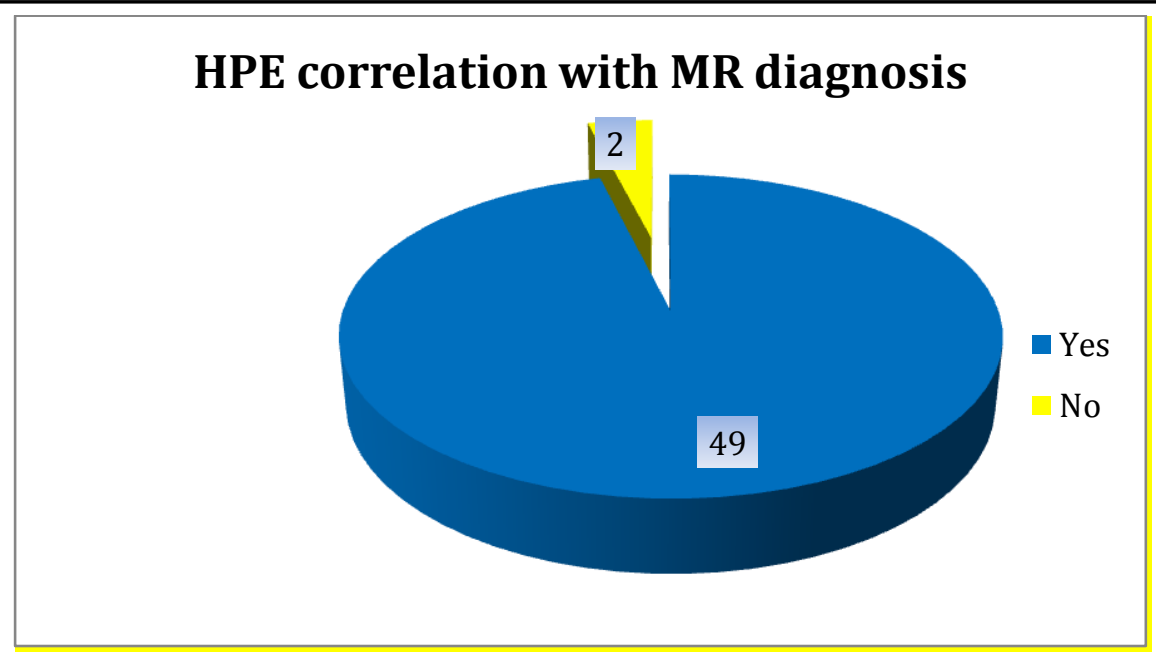

Figure 8: HP Correlation with MR diagnosis

Distribution of patients according to enhancement pattern observed on post Gadolinium images showed that out of the patients who were given IV Gadolinium, the maximum number of lesions showed heterogeneous enhancement pattern
(69.6\%), followed by 9 lesions(19.6\%)which showed homogeneous enhancement pattern. 5 lesions $(10 \%)$ showed peripheral /enhancement of only wall/septae .None of the lesions were purely non-enhancing.

Table 8: Distribution of patients according to Post contrast enhancement

\begin{tabular}{|l|c|c|}
\hline Enhancement & No. of patients & Percentage \\
\hline Homogenous & 9 & $19.57 \%$ \\
\hline Heterogeneous & 32 & $69.57 \%$ \\
\hline Peripheral & 5 & $10.87 \%$ \\
\hline Non-enhancing & 0 & $0.00 \%$ \\
\hline Total & 46 & 100.0 \\
\hline
\end{tabular}

Distribution of patients with cervical carcinoma according to the stages as per FIGO staging of classification for cervical cancer showed that maximum number of patients had Stage IIA disease $(30.8 \%)$ followed by 3 patients $(23.1 \%)$ having Stage IIB disease. 2 patients (15.4\%) each were having Stage IVA and IVB disease 1 patient each had Stage IB and IIIB disease (7\%). None of the patients were observed having Stage IA or Stage IIIA disease. Out of 5 patients with ovarian carcinoma stage IA and $3 \mathrm{~B}$ was seen in $4(80 \%)$ and $1(20 \%)$ patients respectively. Both patients of carcinoma endometrium were found to be having stage IB.

Table 14: Distribution of patients with carcinoma cervix, ovary and endometrium according to FIGO staging

\begin{tabular}{|l|c|c|c|}
\hline \multirow{4}{*}{ Carcinoma Cervix } & Stage & No. of patients & Percentage \\
\cline { 2 - 4 } & IA & 0 & 0.0 \\
\cline { 2 - 4 } & IB & 1 & 7.7 \\
\cline { 2 - 4 } & IIA & 4 & 30.8 \\
\cline { 2 - 4 } & IIB & 3 & 23.1 \\
\cline { 2 - 4 } & IIIA & 0 & 0.0 \\
\cline { 2 - 4 } & IIIB & 1 & 7.7 \\
\cline { 2 - 4 } & IVA & 2 & 15.4 \\
\cline { 2 - 4 } & IVB & 2 & 15.4 \\
\cline { 2 - 4 } & TOTAL & $\mathbf{1 3}$ & $\mathbf{1 0 0 . 0}$ \\
\hline Carcinoma Ovary & IA & 4 & 80.0 \\
\hline
\end{tabular}




\begin{tabular}{|l|c|c|c|}
\hline \multirow{4}{*}{} & IB & 0 & 0 \\
\cline { 2 - 4 } & IC & 0 & 0 \\
\cline { 2 - 4 } & IIA & 0 & 0 \\
\cline { 2 - 4 } & IIB & 0 & 0 \\
\cline { 2 - 4 } & IIIA & 0 & 0 \\
\cline { 2 - 4 } & IIIB & 1 & 20.0 \\
\cline { 2 - 4 } & IIIC & 0 & 0 \\
\cline { 2 - 4 } & IVA & 0 & 0 \\
\cline { 2 - 4 } Earcinoma & IVB & 0 & 0 \\
\cline { 2 - 4 } & TOTAL & 5 & 100 \\
\cline { 2 - 4 } & IA & 0 & 0 \\
\cline { 2 - 4 } & IB & 2 & 0 \\
\cline { 2 - 4 } & II & 0 & 0 \\
\cline { 2 - 4 } & IIIA & 0 & 0 \\
\cline { 2 - 4 } & IIIB & 0 & 0 \\
\cline { 2 - 4 } & IIIC & 0 & 0 \\
\cline { 2 - 4 } & IVA & 0 & 0 \\
\cline { 2 - 4 } & IVB & 0 & 0 \\
\cline { 2 - 4 } & Total & 0 & 0 \\
\hline
\end{tabular}
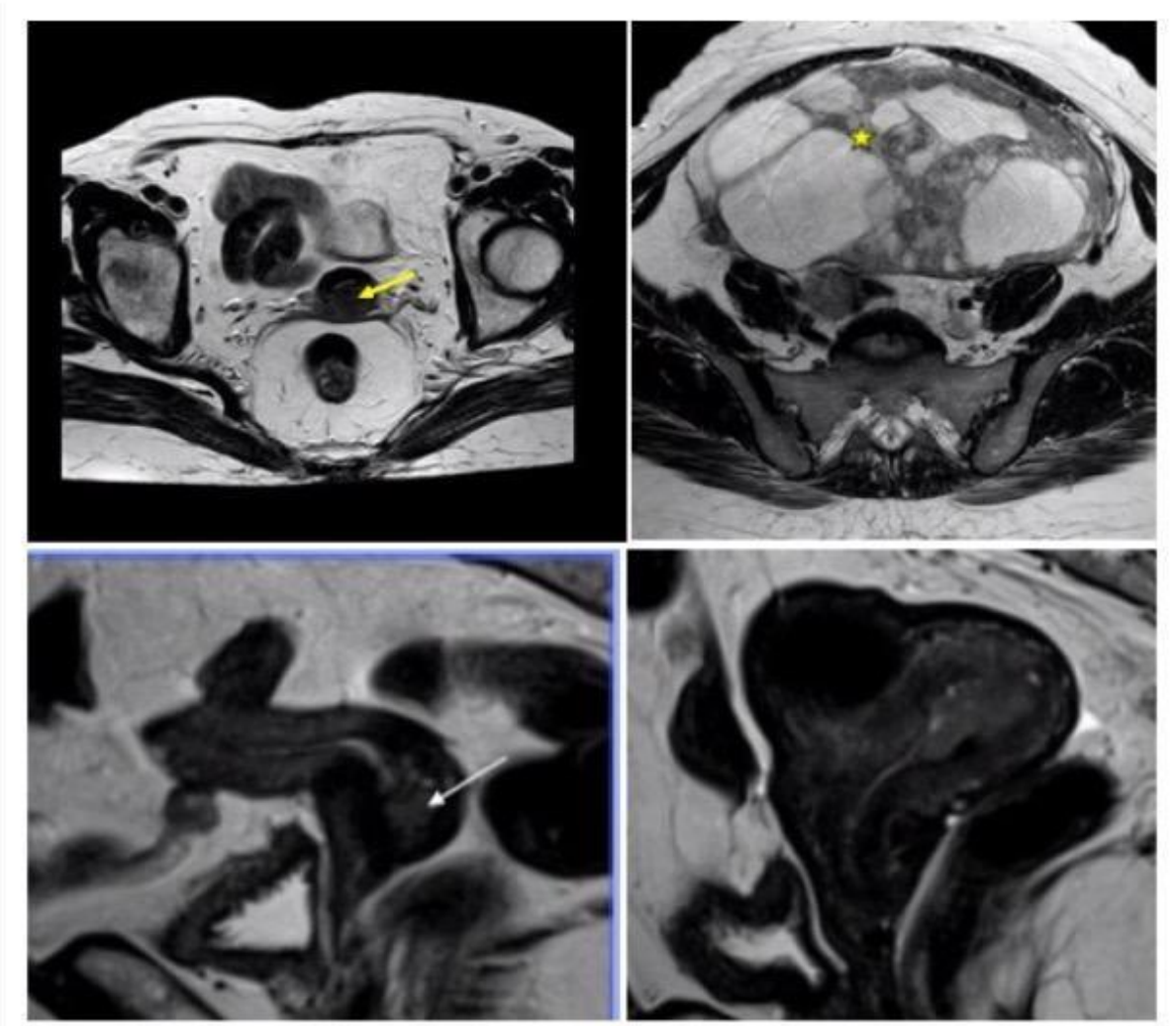

Figure 9: Malignant Lesions (Clockwise from left upper corner). cervical carcinoma, Mucinous cystadenocarcinoma, cervical carcinoma and endometrial carcinoma.

\section{Discussion}

The present study consisted of 75 patients who presented with gynecological complaints for pelvic MRI to the Department of Radiology, Mahatma Gandhi Institute of Medical Sciences Aurangabad. The maximum number of patients was in the age group $21-30$ years (n-16). The age group of less than 10 years shows the least number of patients (n-2). The mean age with standard deviation was $38.73 \pm 18.62$ years. Similar study conducted by Imaoka et al found that most cases were in the age group of $30-55$ years ${ }^{11}$. The 
most common complaint in our study was observed to be post-menopausal bleeding .The most common etiology was found to be neoplastic with 22 patients ( $29 \%$ ) having pathologies due to neoplastic etiology followed by 19 patients $(25 \%)$ with pathologies related to congenital anomalies. We distributed all the pathologies into three categories according to their nature- benign, malignant and congenital. Benign pathologies were found in maximum number (n-29) of our patients .Our findings were found to be similar study conducted by Choudhary s et al. in which benign pathologies were common ${ }^{12}$.

We distributed all the patients according to the anatomical site of origin/primary structure involved. Uterus was found to be the most common structure involved i.e. 45 patients were observed having involvement of the uterus as the primary structure to be involved. A study conducted by Ascher S.M also showed similar findings i.e. myometrium was the most common structure to be involved along with cervix ${ }^{13}$. We distributed patients according to uterine pathologies. The most common malignant pathology was found to be carcinoma cervix (n13). The most common congenital anomalies of uterus were bicornuate and hypoplastic uterus (n7) .The most common benign pathology of uterus was found to be fibroids (n-6) as per our study. Study done by Togashi et al also shows that leiomyoma was more common than rest of benign uterine pathologies ${ }^{14}$.

On MRI out of the 6 patients having fibroids, 4 patients had intramural fibroids while two had subserosal fibroids. This correlated correctly with post-operative findings and histopathological examination in which 4 were intramural and 2 were subserosal uterine leiomyomas. Zawin $\mathrm{M}$ et al conducted a study in which he obtained similar results. In his study out of the total 31 fibroids detected on MRI majority of them were intramural in location ${ }^{15}$. There were 5 cases of adenomyosis of all the uterine pathologies .4 of them were diagnosed on MRI as diffuse adenomyosis while one of them was diagnosed as focal adenomyosis.
On histopathology 4 were diagnosed as adenomyosis while the one diagnosed as focal adenomyosis turned out to be normal uterine tissue.

MRI is an accurate non invasive imaging modality for diagnosing adenomyosis with a high sensitivity (78-88\%) and specificity (67-93\%) as studied by Reinhold $\mathrm{C}$ et $\mathrm{al}^{16}$. Out of the 14 patients having ovarian/adnexal pathologies, the maximum numbers of patients were found to have complex unilateral ovarian cyst ( $n-5)$. According to a study done by Dwivedi AN et al, MRI was 97.7\% sensitive and $73.1 \%$ specific for diagnosing a mass of ovarian origin ${ }^{17}$. Ahmad et al stated the magnetic resonance imaging is an excellent modality for non-invasive evaluation of adnexal masses and for assessing the nature and origin of various pathologies because of excellent spatial resolution and tissue contrast resolution, great tissue characterization and multiplanar imaging capabilities without any risk of ionizing radiation $^{18}$.

The analysis of congenital uterine anomalies showed that the maximum numbers of patients were observed having bicornuate and hypoplastic uterus (n- 7). These observations don't correlate with the studies conducted by Homer HA et al, Raga $\mathrm{F}$ et al and Fedele $\mathrm{L}$ et al who found that septate uterus is the most common Müllerian duct anomaly ${ }^{19,20,21}$. Distribution of patients according to tissue content and anatomical origin of pathologies was studied. The maximum numbers of uterine lesions were solid in nature (n-20).

Avascular malformation of uterus appearing cystic in nature was observed in one patient in our study. On MRI it appeared as a focal uterine mass in the fundus of the uterus with serpiginous low voids in the myometrium, showing intense enhancement on post contrast images. Maximum number of cervical lesions (n-13) and lesions of vagina and vulva (n-3) were solid in nature. Maximum number of lesions in ovary and adnexa were solidcystic in nature (n-7). 5 lesions were purely cystic in nature.

We studied age wise distribution of 75 patients 
with according to the nature of the pathology. Congenital anomalies were seen in patients in the age groups of 11-30 years. Maximum numbers of benign pathologies were seen in the age groups of 41-50 years while none in the age group of 75 years and above. Of all the patients having malignant pathologies, there were 6 patients seen each in the age group of $51-60$ years and $61-70$ years and none in younger age groups(A and B).We studied age distribution of patients according to malignant lesions. The maximum numbers of patients were seen having cervical carcinoma (n-13). Out of these patients, most of them were belonging to age group 41-70 years and none in the age group of 0 - 10 years. There were 2 patients each in age groups of 11-40 years and more than 70 years. Patients typically present between $4^{\text {th }}$ and $7^{\text {th }}$ decades of life, with mean age of presentation being 53 years according to $\mathrm{Y}$ Yamashita et $\mathrm{al}^{22}$.

12 out of 13 cases were histopathologically proven to be squamous cell carcinoma and 1 lesion was proven to be well differentiated adenosquamous carcinoma. A study by Szklaruk J et al also had similar findings i.e., $90 \%$ of cervical carcinomas were squamous cell carcinoma, followed by adenosquamous carcinoma $^{23}$.

In our study, appearance as well as extension of each lesion varied according to the stage of the lesion i.e. 4 lesions belonged to FIGO stage IIA(30\%), followed by 3 patients(23\%) having Stage IIB disease. 2 patients each were having Stage IVA and IVB disease(15\%),1 patient each having Stage IB and IIIB disease(7\%). The National Cancer Registry Programme stated in their 2009 report that there were 90,708 cases of carcinoma cervix in 2007 in India making carcinoma cervix the commonest malignancy affecting the female genital tract $^{24}$.

Ovarian tumors were observed in 6 patients .Out of these 3 patients belonged to the age group of 41 -70 years, followed by 2 patients in the age group of 11-40 years and 1 patient in the age group of more than 70 years. The maximum number of patients having ovarian tumors were having serous cystadenoma (n- 3), 2 were having mucinous cystadenoma (n-2) while one patient had mucinous cystadenocarcinoma (n-1). A study done by Seidman JD et al. stated that mucinous tumours are less common than serous neoplasms ${ }^{25}$. Two of the serous cystadenomas presented as large thin walled, uniloculated cystic masses on MRI .One was multilocular with thin septations .Papillary projections were noted in two of them. All of them showed low signal intensity on T1 weighted images and high signal intensity on T2 weighted images. The septations were hypointense on $\mathrm{T} 1$ and $\mathrm{T} 2$ weighted sequences.

\section{Conclusion}

MRI is found to be an excellent non-invasive tool for diagnosis of uterine and adnexal pathologies. It has got a high sensitivity and specificity for the diagnosis of congenital as well as benign and malignant pathologies of uterus and adnexa. MRI not only helps in identification of gynecological malignancies but also is immensely accurate in identifying early infiltration of adjacent structures as well as lymph nodal infiltration thus being useful in correct staging of the malignancies thereby helping in planning of appropriate treatment strategy for the patient.

\section{References}

1. Punwani S. Contrast enhanced MR imaging of female pelvic cancers: Established methods and emerging applications. Eur J Radiol. 2011;78:2-11.

2. Saez F, Urresola A, Larena JA, et al. Endometrial carcinoma: Assessment of myometrial invasion with plain and gadolinium-enhanced MR imaging. J Magn Reson Imaging. 2000;12:460-466.

3. Koyama T, Tamai K, Togashi K. Staging of carcinoma of the uterine cervix and endometrium. Eur Radiol. 2007;17:20092019.

4. Burn PR, McCall JM, Chinn RJ, et al. Uterine fibroleiomyoma: MR imaging 
appearances before and after embolization of uterine arteries. Radiology. 2000; 214:729-734.

5. Harman M, Zeteroglu S, Arslan H, et al. Predictive value of magnetic resonance imaging signal and contrast-enhancement characteristics on post embolization volume reduction of uterine fibroids. Acta Radiol. 2006;47:427-435.

6. Ascher SM, Arnold LL, Patt RH, et al. Adenomyosis: Prospective comparison of MR imaging and transvaginal sonography. Radiology. 1994;190:803-806.

7. Ramanathan S, Kumar D, Khanna M, et al. Multi-modality imaging review of congenital abnormalities of kidney and upper urinary tract. World J Radiol. 2016;8(2):132-41.

8. Chou CK, Liu GC, Chen LT, Jaw TS. MRI manifestations of peritoneal carcinomatosis. Gastrointest Radiol. 1992 Fall;17(4):336-8.

9. Tamai K, Koyama T, Saga T, et al. The utility of diffusion-weighted MR imaging for differentiating uterine sarcomas from benign leiomyomas. Eur Radiol. 2008;18:723-730.

10. Koyama T, Togashi K. Functional MR imaging of the female pelvis. $J$ MagnReson Imaging. 2007;25:1101-1112.

11. Imaoka I, Sugimura K, Masui T, et al. Abnormal uterine cavity: Differential diagnosis with MR imaging. MagnReson Imaging. 1999;17:1445-1455.

12. Chaudhry S, Reinhold C, Guermazi A, et al. Benign and malignant diseases of the endometrium. Top MagnReson Imaging. 2003;14:339-357.

13. Ascher, S.M., MR imaging of the female pelvis: the time has come. Radiographics, 1998.18(4): p. 931-45.

14. Togashi K, Ozasa H, Konishi I, et al. Enlarged uterus: Differentiation between adenomyosis and leiomyoma with MR imaging. Radiology. 1989;171:531-534.
15. Zawin, M., et al., High-field MRI and US evaluation of the pelvis in women with leiomyomas. Magn Reson Imaging, 1990. 8(4): p. 371-6.

16. Reinhold C, McCarthy S, Bret PM ,et al .Diffuse adenomyosis :comparision of endovaginal US and MR imaging with histopathologic correlation. Radiology 1996;199:151-158.

17. Dwivedi AND, Jain S ,Shukla RC, Jain M, Srivastava A, Verma A .MRI is a state of art imaging modality in characterisation of indeterminate adnexal masses. $\mathrm{J}$. Biomedical Science and Engineering 2013;(6):309-313.

18. Ahmad,I, Kiramani ,S ,Rashid, $\mathrm{M}$ and Ahmad, K(2011)MR imaging of adnexal masses:A review .NJR, 1,54-60.

19. Homer HA.LiTC, Cooke ID. The septate uterus: a review of management and reproductive outcome .FertilSteril 2000;73(1) 1-14.

20. Raga F,Bauset C ,Remohi J ,BonillaMusoles F,Simon C, Pellicer A. Reproductive impact of congenital mullerian anomalies .Hum Reprod 1997:12(10):2277-2281.

21. Fedele L, Bianchi S. Hysteroscopicmetroplasty for septate uterus .Obstet Gynecol Clin North Am 1995;22(3):473489.

22. Y Yamashita, Torashima M, Hatanaka Y, Harada M, Higashida Y, Takahashi M, Mizutani H, Tashiro $\mathrm{H}$, Iwamasa J, Miyazaki $\mathrm{K}$ et al.Adnexal masses :accuracy of characterisation with transvaginal US and precontrast and postcontrast MR imaging.Radiology.1995 Feb;194(2):557-65.

23. Szklaruk J, Tamm EP ,Choi H, Varavithya V.MR Imaging of common and uncommon large pelvic masses, Radiographics ,2003;23:403-24. 
24. National Cancer Registry Programme (NCRP, I., Time trends in cancer incidence rates: 1982-2005. Bangalore. 2009.

25. Siedman JD, Russell P, Kurman RJ. Surface epithelial tumours of ovary. In :Kurman RJ, editor. Blaustein's pathology of female genital tract, $5^{\text {th }}$ ed, New York :Springer Verlag;2002, pp.791-904. 